Canadian Journal of Educational Administration and Policy

CJEAP

Revue canadienne en administration et politique de l'éducation

\title{
Winton, S., \& Parekh, G. (Eds.). (2020). Critical Perspectives on Education Policy and Schools, Families, and Communities
}

\section{Scott Tunison}

Number 196, 2021

URI: https://id.erudit.org/iderudit/1078521ar

DOI: https://doi.org/10.7202/1078521ar

See table of contents

Publisher(s)

Department of Educational Administration, University of Saskatchewan

ISSN

1207-7798 (digital)

Explore this journal

Cite this review

Tunison, S. (2021). Review of [Winton, S., \& Parekh, G. (Eds.). (2020). Critical Perspectives on Education Policy and Schools, Families, and Communities]. Canadian Journal of Educational Administration and Policy / Revue canadienne en administration et politique de l'éducation, (196), 124-127.

https://doi.org/10.7202/1078521ar 


\title{
Winton, S., \& Parekh, G. (Eds.). (2020). Critical Perspectives on Education Policy and Schools, Families, and Communities. Information Age Publishing. Pages: 223. ISBN: 978-1-64113-879-6
}

\author{
Reviewer: Dr. Scott Tunison, University of Saskatchewan
}

Winton, in the introduction to Critical perspectives on education policy and schools, families, and communities, opines that critical policy analysis (CPA) "has much to contribute to the field of [family, school, community] partnerships" (p. xii). This edited book explores the veracity of the assertion by bringing together a diverse group of scholars to present their critical examinations of pragmatic and theoretical aspects of family, school, and community (FSC) partnerships.

Scholars engaged in CPA draw on a "variety of critical perspectives and methods in their exploration of policies, policy contexts, policy processes, policy communities, and policy impact" (Diem et al., 2019, p. 7). Apple (2019) concurs and argues that CPA and other critical theory stances have the "dual task" of helping us to understand "the complexities and power relations of educational policies and practices, and, at the same time, employ critical approaches to document the interruptions, actions, and movements that continually challenge the dominant forms of policy and practice that generate and/or reproduce inequalities" (p. 285). CPA scholars tend to focus on:

- The difference between policy rhetoric and practiced reality

- The policy, its roots, and its development (e.g., how it emerged, what problems it was intended to solve, how it changed and developed over time, and its role in reinforcing the dominant culture)

- The distribution of power, resources, and knowledge as well as the creation of policy "winners" and "losers"

- Social stratification and the broader effect a given policy has on relationships of inequality and privilege

- The nature of resistance to or engagement in policy by members of nondominant groups. (Young \& Diem, 2017, p. 4)

Contributing authors employ a broad range of critical theory frameworks in pursuit of their chosen research foci. No chapter tackles all five concerns typically addressed by CPA-focused research nor do all of them explicitly employ CPA. However, each chapter makes a targeted contribution to our understanding of at least one of these concerns. Furthermore, taken as a whole, the chapters produce a robust picture of the ways in which CPA can enhance our scholarship of policy as well as the ways in which leaders and organisations are manifested in the policy "problems" they choose to tackle and the processes they choose to pursue those problems.

\section{Organisation of Chapters}

All twelve chapters that constitute this book read as mini theses. While brief, each chapter packs a pow- 
erful punch with succinct literature reviews, robust but compact elucidations of the complex theoretical frameworks and methodologies driving the research, and focused descriptions of findings and potential implications for schools, districts, and communities. Of particular interest to Canadian audiences, six of the chapters report research conducted in Canadian jurisdictions. While each chapter is well-framed and skillfully edited, I highlight six chapters below that were particularly influential in shaping my appreciation of $\mathrm{CPA}$ - and associated methodological and conceptual frameworks - as a means of examining FCAs.

In/exclusive engagement of school communities through school district decentralization, Diem et al. reports findings from a Nevada-based project to examine the process of district decentralization. This chapter's review of the literature associated with district decentralization processes and policies and their effects on parent/community engagement is an excellent primer for those new to field. The study referenced in this chapter was one of the few in this book that cites CPA explicitly as its theoretical framework and the authors situate the work firmly in CPA with a particularly effective synopsis of the relevant literature and underlying ontological and epistemological stances. The chapter explores critical questions including: What does it mean to parents/community members to be involved in schools? Who gets to define what involvement ought to look like? and What (and whose) purpose does involvement/ engagement serve schools, students, and communities and what role should each of these groups have in developing policies and procedures that define and direct such activity?

YPAR as policy production: Youth building relationships with home, school and community to mobilize change (Guerrero), frames youth participatory action research (YPAR) as a means of mobilizing education policy "with and for" youth, families, and communities by activating passions and perspectives of youth and engaging them in exploring their own solutions to issues that matter to them. Conducted in Toronto District School Board (Canada), it addresses policy/practice questions such as: "What are the implications for education policy when racialized students engage with youth participatory action research (YPAR)? What are the implications of the youth's work for their academic achievement and well-being? How do these implications figure into the relationships between schools, families, and communities?" (p. 23). YPAR can be a powerful and authentic means of co-creating policy and practice and it aligns well with the critical theory conceptual frameworks employed by other authors published in this book. In this case, YPAR appeared to yield "scaffolded experiential learning with each other [youth, faculty, family, and community] ... and create a new hybrid family, one that addresses topics that are relevant to its members, which in turn engaged them in 'espacio de confianza' (space of trust)" (pp. 36-37).

Even with the best of intentions - that is, to serve the needs of refugee students and families - a district can unintentionally create conflict among staff hired for similar but very different tasks by allowing the work of "boundary spanners" (p. 47) to creep considerably outside policy/practice parameters. To interpret or not to interpret? That is the question for refugee mentors in schools (Koyama \& DeMartino) reports the findings of a mixed-methods ethnographic study of the policies guiding the interpreting services provided by refugee mentors in an urban school district in the United States. "The ambiguity of the district's interpreting policy and the overlap of expertise in the [two student/family language services departments], coupled with the lack of awareness by school administrators, staff, and teachers about who was supposed to translate and interpret in different situations in the schools, led to variable appropriations of the policy" (p. 55). On one hand, refugee mentors felt empowered to decipher policy in the context of their advocacy efforts on behalf of students and families; but, on the other hand, they were placed in untenable positions by others' views of policy and called upon to translate and/or interpret even when it was not a part of their jobs and when it took them away from the jobs they were, by policy, expected to do.

Underwood, Church, and van Rhijn's chapter, entitled Responsible for normal: The contradictory work of families, is one of two chapters in this book that employed institutional ethnography (IE). In this case, IE was used to study the processes families use to navigate the terrain of inclusive education in early childhood education policies contexts in Ontario Canada. Due to their focus on how parents make sense of policy texts, what they do as a result, and what implications the actions/texts have for them, their children, and the system itself, IE was ideally suited for the study because it "proceeds from the details of how people manage their everyday lives to show how those activities are organized through broader policy, economic, and institutional processes" (p. 93). In other words, "once you know how the institution works, what happens?" (p. 100). Some "opt in" - that means complying with whatever expectations the 
system enacts and availing of whatever services may be available; whereas others "opt out" - refuse to see (dis)ability as a pathology to be treated but access services to meet children where they are and to embrace who they are as humans.

The challenge of developing policy that is responsive to real people is that the policy planning process is typically formed through planning for inputs such as human resource needs, budgets for materials, and space requirements ... this bureaucratic process leaves the people whom it intends to serve out of the policy until [they connect to the policy itself] and become outcomes [the policy is designed to 'fix']. (p. 103)

Young's chapter, entitled Applying critical race theory to district-level behavior policy: Empty promises, provides a particularly convincing argument in favour of CPA as a means to examine FCA policy contexts. It makes a key contribution to the book with a concise synopsis of critical race theory (CRT) and extended discussion of the ways in which CRT and CPA can be blended to enhance study of policy and practice. Young states,

By combining CRT and CPA, I add a race-conscious analysis to the examination of policy development, holding race at the center of all aspects of the process. CPA alone would not necessarily uncover issues related to race and definitely not to the extent I am able to by engaging CRT. A CRT-only focus would not have explored the development of the policy and key conversations and viewpoints I discovered through CPA. In layering these theoretical approaches, I am able to deepen my analysis of the policy development through a race-focused lens. (p. 145)

The joint application of CRT and CPA provided a potent foundation to analyze the development of the Jefferson County Board of Education's student behaviour policy as well as the policy text itself. Readers will find Young's sensitive disentanglement of the underlying issues embedded in the behaviour policy and explication of the implications for school boards, educators, families, and community partners to be particularly poignant.

In Parent/caregiver involvement in schools: Rhetoric versus reality, Michelle Young and Bradley Carpenter provide a conceptual framework for studying policies governing parent/caregiver involvement. They argue that their chapter has two purposes:

Demonstrate the utility of examining parent/caregiver involvement policy discourse through the social constructivist perspective, revealing that what historically 'counts' as involvement does not necessarily reflect the lived reality of most caregivers of PK-12 public school students. The second purpose of the chapter is to encourage ... [consideration of] .... Critically oriented studies as fodder in the attempt to intentionally interrupt and displace ill-fitting notions of involvement, and stud move the voices and experiences of parents/caregivers, particularly those from historically marginalized backgrounds, from margin to center. (p. 184)

They make a convincing argument that social constructivist theory is a valuable companion to CPA because it "allows for a nuanced understanding of the complexities associated with a particular issue, problem or policy, from problem finding and framing to the identification, development, implementation, and evaluation of solutions" (p. 194). Their extended discussion of the implications and strategies for strengthening the family, school, community partnerships is particularly insightful. Current public discourse regarding parental/caregiver involvement in schools "legitimates and seeks to enforce a particular normative model of involvement, a model that continues to exclude certain parents and forms of involvement from the realm of acceptability" (p. 195); which often leads to unrealistic expectations for and marginalization of many families. Furthermore, "the public sphere of education ... will fail to meet the needs of our rapidly diversifying society unless power differentials are continuously confronted and ameliorated" (p. 196). 


\section{Reflections}

The research presented in this book is convincingly supportive of Winton's introductory assertion that critical policy analysis is an effective means of examining family, school, community partnerships that opens the door to unique insights not likely to emerge from traditional approaches to policy studies.

In fleshing out this book, the editors brought together prominent authors widely recognized for their critical policy analysis scholarship along with several researchers who, while they may not yet be as well-known in the field, are using CPA and associated critical methodologies effectively in pursuit of new social justice-tinged insights about policy, leadership, and family-school-community engagement.

Young and Diem - among the prominent contributors to this book - observed elsewhere "the study of educational policy through a critical frame allows for a nuanced, holistic understanding of the complexities associated with education policy, from problem finding and framing to policy development, implementation, and evaluation" (2018, p. 79). Taken as a whole, the diverse research presented in this book paints a holistic picture of family, school, community partnerships and the policies and practices that affect them.

\section{References:}

Apple, M. (2019). On doing critical policy analysis. Educational Policy, 33(1), 276-287.

Diem, S., Young, M. D., \& Sampson, C. (2019). Where critical policy meets the politics of education: An introduction. Educational Policy, 33(1), 3-15.

Young, M. D., \& Diem, S. (2017). Critical approaches to education policy analysis: Moving beyond tradition. Springer.

Young, M. D., \& Diem, S. (2018). Doing critical policy analysis in education research: An emerging paradigm. In C. Lochmiller (Ed.), Complementary research methods for educational leadership and policy studies (pp. 79-98). Springer. 